\title{
Decompressive Hemicraniectomy Remains a Physician's Individual Decision
}

Catharina Keller*, Henning Stetefeld ${ }^{*}$

Universitätsklinikum Köln, Klinik für Neurologie, Kerpenerstrasse 62, 50924 Köln, Germany

"Corresponding author: Catharina Keller, Henning Stetefeld Department of Neurology, University Hospital Cologne, Kerpener Str. 62, D-50937 Cologne, Germany, Tel: +49-221-478-4029; Fax: +49-221-478-6454; E-mail: catharina.keller@uk-koeln.de

Dr. Henning Stetefeld, Department of Neurology, University Hospital Cologne, Kerpener Str. 62, D-50937 Cologne, Germany, Tel: +49 2214784029 , Fax: +49 221478 6454; E-mail: henning.stetefeld@uk-koeln.de

Received date: May 20, 2014, Accepted date: May 28, 2014, Published date: June 03, 2014

Copyright: (c) 2014 Keller C, et al. This is an open-access article distributed under the terms of the Creative Commons Attribution License, which permits unrestricted use, distribution, and reproduction in any medium, provided the original author and source are credited.

\begin{abstract}
Although the latest trials (DESTINY, DESTINY II, HAMLET, DECIMAL) have provided evidence that decompressive hemicraniectomy in malignant MCA infarction (MMI) can improve survival rates and neurological outcomes, the decision for or against the procedure remains challenging in respect of the inclusion and exclusion criteria, such as the definition of MMI, severity of symptoms at stroke onset and neuroimaging findings.

This report focuses on a young patient who suffered an MMI of the right hemisphere. Because of a rapid deterioration in the clinical symptoms, we decided to perform an early decompressive hemicraniectomy after $24 \mathrm{~h}$. The patient survived without any complications, and with a favourable outcome (mRS 1).

The case shows that young patients in particular can have a remarkable potential for full recovery after an MMI, and that the benefits of surgery outweigh the risks, provided that 1) the hemicraniectomy is performed promptly (after careful consideration of whether brain swelling might occur soon after MMI), and 2) the elective brain territories have not yet been affected.
\end{abstract}

Keywords: Malignant MCA infarction (MMI); Brain edema; Hemicraniectomy; NIHSS

\section{Case Report}

The term malignant MCA infarction (MMI) was first used in 1996, however, there is still no generally accepted definition for this term, with the major studies to date having chosen clinical criteria to describe this condition, i.e. the severity of neurological symptoms at stroke onset $($ NIHSS $=$ National Institute for Health Stroke Scale), rapid deterioration in symptoms, and neuroimaging findings [1-6].

As yet, life threatening edema has been ruled out if at least two thirds of the MCA vascular territory or more than $50 \%$ of the MCA vascular territory are affected, or more than $82 \mathrm{ml}$ on a DWI (diffusion weighted image) MRI sequence within the first $6 \mathrm{~h}$ after stroke onset, or more than $145 \mathrm{ml}$ on DWI sequence within the first $14 \mathrm{~h}$ after stroke onset are affected [7-9].

Besides the DESTINY trial, no other study has exclusively mentioned brain territories that have been affected by stroke, with DESTINY including those patients whose basal ganglia were at least partially affected [4].

As it seems somewhat challenging to arrive at a true definition of $+\mathrm{MMI}$ based on the early onset of clinical symptoms, it might prove valuable to consider not only the vascular territories, but also the elective brain territories, in order to define an MMI in which life threatening edema occurs. A precise evaluation of the affected brain territories might also be important to estimate the outcome of the modified Rankin scale after rehabilitation of the individual patient.
We report the case of a 44 year old patient who suffered a repeated middle artery infarction of the right hemisphere in May 2011. The patient was admitted to our stroke unit due to a rapidly recurring leftsided brachio-facial hemiparesis, which was accompanied by a severe headache but no loss of consciousness. The NIHSS at stroke onset was 10 points.

The first CCT scan showed a right-hemispheric middle artery infarction within the frontal region (Figure 1) as well as an old left hemispheric infarction (but without any remaining neurological symptoms). As a result of the exacerbation of symptoms within one day, and with severe left-sided hemiparesis accompanied by a total neglect of the left side, a second CCT scan was performed. The NIHSS at this stage was 18 points.

The CCT scan revealed a second widespread cerebral artery infarction with more than two-thirds of the vascular MCA territory affected (Figure 2). There was also a slight compression of the right ventricle, but no midline shift, while the basal ganglia of the right hemisphere did not seem to be affected (Figure 2). The patient soon developed acute clinical symptoms of brain pressure (drowsiness, slow light reaction of the pupils, increased hemiparesis); thus, we decided to perform an early decompressive hemicraniectomy due to a suspected MMI (Figure 3A, 3B: after re-implantation of the right cranium).

The post-surgery monitoring revealed the presence of paroxysmal atrial fibrillation, which was the likely cause of the (bi-) hemispheric strokes. We treated the patient with systemic anti-coagulation using heparin (increasing the starting PTT two to three times), and later with oral dabigatran (150mg twice daily). Three days after surgery, we transferred the patient to our early rehabilitation program. Subsequently, the patient was transferred to a neurological 
Citation: Keller C, Stetefeld H (2014) Decompressive Hemicraniectomy Remains a Physician's Individual Decision. J Neurol Neurophysiol 5:

rehabilitation clinic for several months (when he left our clinic the NIHSS score was 4 and the mRS score was 2), and continued later with physiotherapy and ergotherapy. Despite the presence of sensory deficiency on the left side, no neurological symptoms were obvious. The patient was able to participate actively in all daily activities, and returned to his workplace eight months after the stroke. Our patient is an outstanding example of a near complete recovery after an MMI10 by early hemicraniectomy.

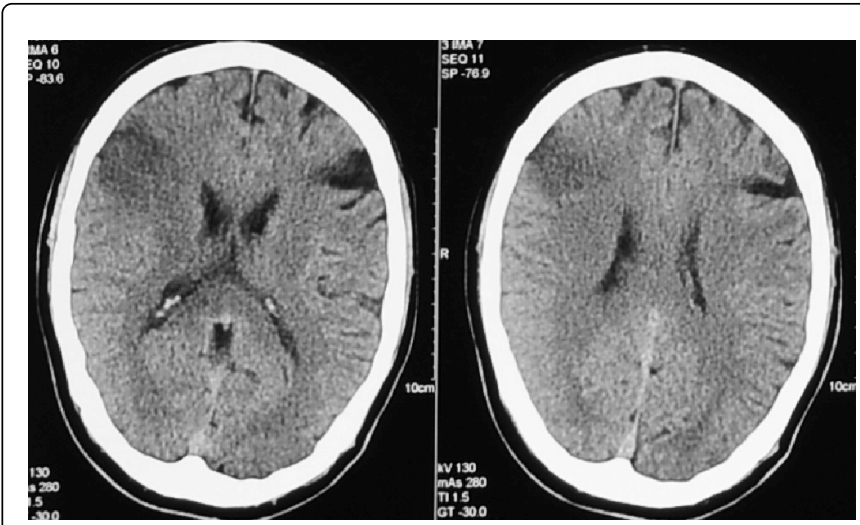

Figure 1: First CCT scan, acquired after the first stroke

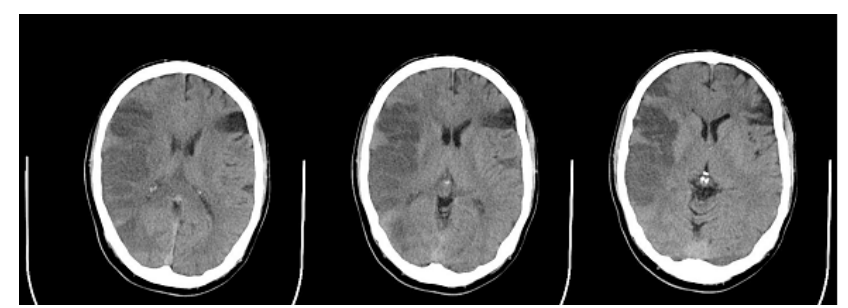

Figure 2: Second CCT scan, acquired after the second stroke, showing the beginning of oedema of the right hemisphere.

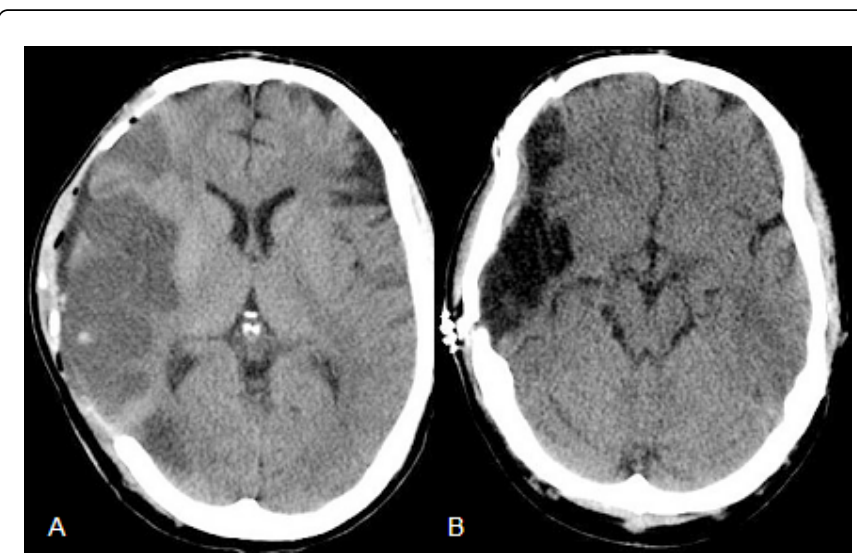

Figure 3: (A) 3 days after hemicraniectomy. (B) 3 months after hemicraniectomy, after reimplantation of the right cranium.

Concerning the DESTINY trial, our patient is unlikely to have been recommended for hemicraniectomy because the basal ganglia were not affected, the NIHSS score at symptom onset was only 10 points, and he had previously suffered from a small frontal left hemispheric infarction, although without any neurological symptoms remaining (Figures 1-3). Nevertheless, we considered the stroke in this case as an MMI, given the vascular territory affected, the poor NIHSS score and the rapid deterioration in clinical symptoms over a $24 \mathrm{~h}$ period.

Due to the probability that the basal ganglia might be affected by severe brain swelling without an early hemicraniectomy, the concerning mRS result and the worsening of the clinical symptoms, we decided to perform early surgery. A further point influencing our decision for surgery was the age of our patient. The aforementioned trials [2,4,6], excluding DESTINY II [3], all included patients between the ages of 18 and 60, or up to 55 years (DECIMAL[6]); the DESTINY II trial included patients older than 61 years [3].

The final results of the DESTINY II study now confirm that decompressive hemicraniectomy increased survival without severe disability among patients 61 years of age or older and with brain swelling after a malignant middle-cerebral-artery stroke. Therefore, elderly patients have a similar potential for favorable outcome, considered as $\mathrm{mRS}<4$ or 3 , as per the younger patients. Nevertheless, approving this procedure remains an individual decision that depends on the biological age, the patient's presumable will to survive in a more challenging post-operative condition, and any secondary lifethreatening diseases.

The required NIHSS at symptom onset was a further point of consideration, which should be higher than 14 out of 42 points for both hemispheres. Our patient initially had an NIHSS score of 10, and then after the deterioration of symptoms we scored the NIHSS with 18 points. The DECIMAL trial set a high NIHSS score of at least 16 points for both hemispheres, while the HAMLET, DESTINY and DESTINY II trials also differed between the left (dominant) and right (nondominant) hemispheres [2-4].

The following results of our clinical considerations confirm our decision for hemicraniectomy: first, young patients have a remarkable potential for full recovery after an MMI [10]; second, if the basal ganglia are not affected by the stroke, the overall expected outcome (mRS) might be more favorable; and third, the benefits of an (early) hemicraniectomy (within the first 48h), performed after careful consideration of whether brain swelling might occur soon after MMI, outweigh the risk of surgery in young patients [11-15].

Therefore, clinicians should be aware of the potential for performing early hemicraniectomy in patients in good health but with severe brain damage, in order to prevent the symptoms of brain swelling and additional brain damage resulting from swelling.

\section{References}

1. Hacke W, Schwab S, Horn M, Spranger M, De Georgia M, et al. (1996) 'Malignant' middle cerebral artery territory infarction: clinical course and prognostic signs. Arch Neurol 53: 309-315.

2. Hofmeijer J, Kappelle LJ, Algra A, Amelink GJ, van Gijn J, et al. (2009) Surgical decompression for space-occupying cerebral infarction (the Hemicraniectomy after Middle Cerebral Artery infarction with Lifethreatening Edema Trial HAMLET): a multicentre, open, randomized trial. Lancet Neurol 8: 326-333.

3. Jüttler E, Bösel J, Amiri H, Schiller P, Limprecht R, et al. (2011) DESTINY II: DEcompressive Surgery for the Treatment of malignant INfarction of the middle cerebral arterY II. Int J Stroke 6: 79-86

4. Jüttler E, Schwab S, Schmiedek P, Unterberg A, Hennerici M, et al. (2007) Decompressive Surgery for the Treatment of Malignant Infarction of the 
Citation: Keller C, Stetefeld H (2014) Decompressive Hemicraniectomy Remains a Physician's Individual Decision. J Neurol Neurophysiol 5: 211. doi:10.4172/2155-9562-5-1000211

Page 3 of 3

Middle Cerebral Artery (DESTINY): a randomized, controlled trial Stroke 38: 2518-2525.

5. Vahedi K, Hofmeijer J, Juettler E, Vicaut E, George B, et al. (2007) Early decompressive surgery in malignant infarction of the middle cerebral artery: a pooled analysis of three randomised controlled trials. Lancet Neurol 6: 215-222.

6. Vahedi K, Vicaut E, Mateo J, Kurz A, Orabi M, et al. (2007) Sequential design, multicenter, randomized, controlled trial of early decompressive craniectomy in malignant cerebral artery infarction (DECIMAL Trial). Stroke 38: 2506-2517.

7. Oppenheim C, Samson Y, Manaï R, Lalam T, Vandamme X, et al. (2000) Prediction of malignant middle cerebral artery infarction by diffusionweighted imaging. Stroke 31: 2175-2181.

8. Thomalla G, Hartmann F, Juettler E, Singer OC, Lehnhardt FG, et al. (2010) Prediction of malignant middle cerebral artery infarction by magnetic resonance imaging within 6 hours of symptom onset: A prospective multicenter observational study. Ann Neurol 68: 435- 445.

9. Thomalla GJ, Kucinski T, Schoder V, Fiehler J, Knab R, et al. (2003) Prediction of malignant middle cerebral artery infarction by early perfusion- and diffusion-weighted magnetic resonance imaging. Stroke 34: 1892-1899.
10. Dohmen C, Galldiks N, Bosche B, Kracht L, Graf R (2012) The severity of ischemia determines and predicts malignant brain edema in patients with large middle cerebral artery infarction. Cerebrovasc Dis 33: 1-7.

11. Rieke K, Schwab S, Krieger D, von Kummer R, Aschoff A, et al. (1995) Decompressive surgery in space-occupying hemispheric infarction: results of an open, prospective trial. Crit Care Med 23: 1576-1587.

12. Sarov M, Guichard JP, Chibarro S, Guettard E, Godin O, et al. (2010) Sinking skin flap syndrome and paradoxical herniation after hemicraniectomy for malignant hemispheric infarction. Stroke 41: 560-562.

13. Schwab S, Steiner T, Aschoff A, Schwarz S, Steiner HH, et al. (1998) Early hemicraniectomy in patients with complete middle cerebral artery infarction. Stroke 29: 1888-1893.

14. Uhl E, Kreth FW, Elias B, Goldammer A, Hempelmann RG, et al. (2004) Outcome and prognostic factors of hemicraniectomy for space occupying cerebral infarction. J Neurol Neurosurg Psychiatry 75: 270-274.

15. Huttner HB, Schwab S (2009) Malignant middle cerebral artery infarction: clinical characteristics, treatment strategies, and future perspectives. Lancet Neurol 8: 949-958. 